\title{
Polio Vaccination Literacy Among Mothers of Selected Barangay Health Centers in a Component City
}

\author{
Kristine Anne C. Vinco \\ South Bacolod General Hospital and Medical Center Inc. Philippines \\ kadcelis@gmail.com
}

\author{
Xerxes G. Malaga \\ Western Visayas Center for Health and Development, Philippines \\ xerxesmalaga@gmail.com
}

\begin{abstract}
Every health worker strikes hard for every child's death, most notably when it is due to a disease that is readily preventable with a safe and effective vaccine. The tragedy is hard to accept when health practitioners see the consequences of children missing out on vaccination first-hand. This research was intended to bridge the literature gap on the knowledge, and the reasons mothers comply with polio vaccination. The study was intended to assess the level of literacy on polio vaccination of mothers in selected barangays in Bago City when they are taken as a whole and grouped according to age, educational attainment, distance to health facility, number of children, family income, and barangay location administered. A descriptivecomparative research design using a very highly reliable and valid researcher made questionnaire was administered to respondents. The level of literacy of mothers on polio vaccination in selected barangays of Bago City when grouped according to age, educational attainment, the distance of health facility, number of children, family income, and barangay location was very high. The major reasons for compliance of mothers with polio vaccination can be attributed to health workers who can give follow up through home visits and any health professional who can give the polio vaccine. Due to reported vaccine scare and the current pandemic the study will benefit rural health administrators, community health nurses, and future researchers. Findings could provide rural health administrators with insights to conduct a re-assessment of the implementation of vaccination programs initiated by the Department of Health.
\end{abstract}

Keywords. Health, Community Health, Polio, Vaccination, Literacy, Mothers, DescriptiveComparative, Barangay Health Centers, Bago City.

\section{Introduction}

In 2012, the World Health Assembly gathered and formulated the Decade of Vaccines' adoption, presented through the Global Vaccine Action Plan for 2011-2020. Its objective was to prevent millions of deaths through more equitable access to the benefits of 
vaccination to people in all communities. With this, the Global Alliance for Vaccines and Immunization (GAVI) came into existence and played a critical role in its effort to finance and facilitate delivery platforms for vaccines. It is focused on support for achievements received from vaccination coverage, which has dramatically improved (WHO, 2020).

Every health worker strikes hard for every child's death, most notably when it is due to a disease that is readily preventable with a safe and effective vaccine. The tragedy is hard to accept when health practitioners see the consequences of children missing out on vaccination first-hand. Health authorities see that parents, most especially mothers, are no longer aware of the danger of these diseases, and many children were damaged because of them. Lack of awareness has led to their exposure to illnesses, and the reasons for children not getting their vaccines are diverse. The majority are the consequence of a fundamental lack of access to vaccination services and knowledge of vaccines' basics and compliance. Since the launching of the Global Polio Eradication Initiative in 1988, the WHO, Rotary International, the US Centers for Disease Control and Prevention, UNICEF, and the Bill and Melinda Gates Foundation took the initiative to eradicate the debilitating disease. These were done through an ambitious mass vaccination campaign, which dramatically reduced paralysis from $99.9 \%$ to 33 in 2018. Polio endemic nations have also been reduced into three, namely: Pakistan, Afghanistan, and Nigeria. It has also re-emerged in countries once declared eradicated like Congo, Ukraine, Syria, Papua New Guinea, Indonesia, Laos, Myanmar, and, most recently, in the Philippines (Matsuzawa, 2019). A year later, after the Philippines was declared polio-free by WHO (2018) in 2000, polio has resurfaced in the scene from a three-year-old girl from Lanao del Sur, while the virus was also detected in Manila's sewage and Davao's waterways. The strain came from the weakened wild poliovirus type 2 contained in the oral vaccine used worldwide. With this development, the Department of Health called for urgent action to protect more children from being infected. Massive vaccination campaigns from all health centers nationwide reached immunization coverage of up to $95 \%$. WHO also said that children in all countries might contract the disease as long as a single child remains infected with poliovirus. The DOH was alerted to re-implement the Republic Act 101152, known as the Mandatory Basic Immunization Act, to counter misbelief because of the Dengvaxia phenomenon (Matsuzawa, 2019).

Locally in Western Visayas, in the year 2016, there were four provinces identified as high risk for the poliovirus. One of these is Negros Occidental, excluding Bacolod City. It recorded the highest number of children under five years old who were target to catch up vaccination in February of the same year. About 220,000 children, including Iloilo, 170,000, Capiz, 60,000, and Antique, 50,000, were due for OPV. The low coverage of these priority provinces was a weak surveillance system and inadequate surveillance places and the worst increasing illiteracy of mothers about vaccination. As OPV coverage decreases, the risk of polio importation increases (Sumerido, 2016).

This research intended to bridge the literature gap on the knowledge and the reasons mothers comply with polio vaccination. In a study conducted by Nanbur (2019), it was stated that public health intervention strategies such as immunization could reduce morbidity and mortality associated with infectious disease. The study revealed that the cause of death in childhood is vaccine-preventable diseases. Mothers who were chosen respondents knew and were most willing to comply and subject their children to polio vaccines. On the contrary, mothers' knowledge and compliance were inadequate. One reason was a negative attitude towards polio immunization. The other reason was that the hospital was the only known source for the literacy of the disease and its prevention. Other factors include a fear that their 
children might get sick and husbands' instruction to take the vaccine. A low level of literacy among mothers was a barrier to compliance (Khan MU, 2015).

All these and more gave the researcher the interest to pursue the study on this topic. Polio has been a dangerous disease that has stricken not only many Filipino children but also children in many countries of the world. The objective of this study was to assess the knowledge of mothers about the disease.

At the same time, it sought to measure compliance as a course of prevention to combat the outbreak recurrence of the disease. The output of the study is a health education program for

mothers.

\section{Framework of the study}

This study was based on the Health Belief Model (HBM) by Irwin M. Rosenstock in 1950s. It highlights how programs need to consider individual beliefs about the problem being addressed and the costs and barriers of changing behavior. According to the Health Belief Model, a person is likely to change behavior if he or she experiences perceived susceptibility/seriousness, perceived benefits, perceived barriers, and perceived self-efficacy. The HBM was used to examine patient motivations for adapting a health-related behavior and assessing health-behavior interventions. Perceived susceptibility addresses a patient's beliefs about the risk of getting a condition, while perceived severity relates to the patient's concerns about the seriousness of a condition or illness. Perceived benefits are related to certain behavior's outcomes to reduce their susceptibility to or severity of an illness. Perceived barriers identify patient's concerns or negative beliefs about health behavior. The HBM has been used extensively to study vaccination beliefs and behaviors and vaccination research to identify patient perceptions of disease and vaccination. HBM domains used in this study include perceived susceptibility, perceived severity, perceived benefits, perceived barriers, cues to action, and perceived self-efficacy (Coe, 2012).

In the study, the mothers' literacy on polio vaccination represents their perceived susceptibility, severity, benefits, and barriers to polio vaccination. Their literacy in the different aspects of polio reflects their belief about polio, which allows them to avail of the vaccination. Their literacy also serves as their self-efficacy to bring their children to the health center for vaccination. Mothers who have a high literacy of the benefits of polio efficiently comply with polio vaccination. All mothers have literacy in polio vaccination since health workers are expected to educate every mother about Expanded Program on Immunization (EPI), including polio vaccination.

\section{Methodology}

The study utilized a descriptive-comparative research design. Descriptive design was used to describe the characteristics of the population or phenomena studied. It does not answer questions about how, when, and why the characteristics are being investigated. The design addresses the "what "issue. More importantly, according to Creswell (2005), the descriptive design is appropriate for studies that would like to investigate what prevailed in the present conditions or relationships, hold opinions and beliefs, and process effects and developing trends. In the study, the characteristics of mothers in selected barangays of Bago City were studied in terms of age, educational attainment, the distance to the health center, and barangay location.

On the other hand, a comparative research design was used to compare two groups to conclude the study. The study was able to identify and analyze similarities and differences between groups. Furthermore, this research design may increase the understanding of 
comparisons that may lead to new insights of all participants involved (Richardson, 2018). In the study, variables were compared to the differences in age, educational attainment, distance to the health center, number of children, family income, and barangay location. This type of research design was appropriate for the study as it has gathered and described the complete picture if there is a significant difference in the literacy of mothers.

Using convenience sampling, the respondents were the 88 mothers in selected barangay health centers in the City of Bago. The Yamane method was used in determining the sample size. The respondents were then classified into a stratum using barangay as the unit. Table 1 illustrates the distribution of respondents.

Table 1. Distribution of Respondents

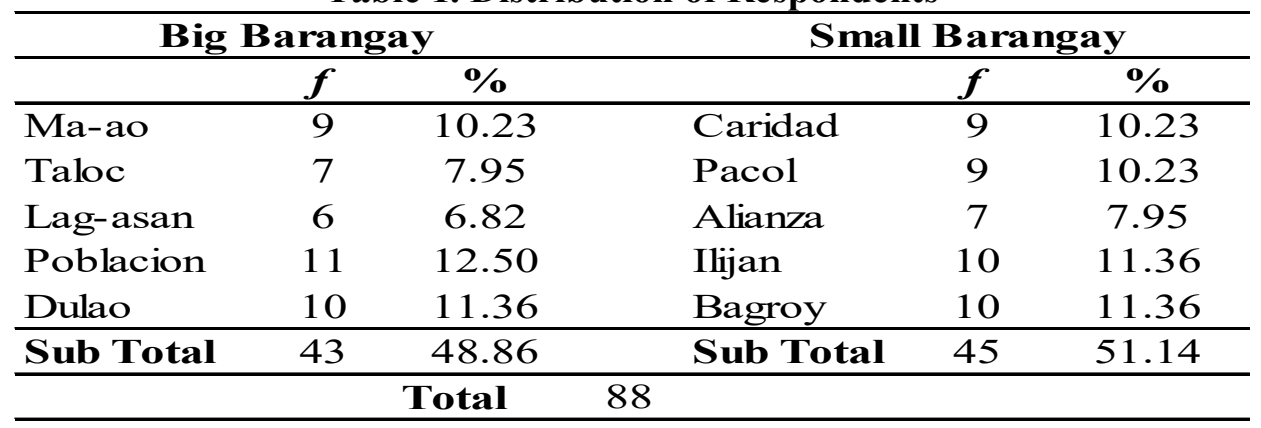

The study utilized a researcher-made instrument. It included questions that enabled to assess the level of literacy of mothers to polio vaccination. A questionnaire was provided to all respondents. The survey instrument consisted of positively and negatively enclosed questions to determine the core dimension of literacy. Part I contained items to identify the profile of mothers, while Part II comprised of items to assess the literacy of mothers on polio vaccination. The four variables were the demographic characteristics of respondents regarding age, educational attainment, distance to the health center, and barangay location. From these findings, significant differences in the said variables were determined. Meanwhile, Part III contained items on compliance reasons and was in the form of a checklist asking the respondents to identify the purposes for submitting their child/children for polio vaccination. Reasons were an increasing number of polio victims; any health professional can give the vaccine; health workers follow up through home visits; readily available; they can be delivered any time; and others, in which the respondents have to list down their reasons for submitting their child/children for polio vaccination.

The said instrument was then subjected to a validity test by professionals who are experts in their chosen fields of endeavor. The criteria of Good and Scates were utilized to determine validity through an evaluation from the three (3) experts. The result has shown an average score of 4.76 , which is very high, thereby confirming the research instrument's validity. The self-made survey instrument was then also subjected to a reliability test. Thirty (30) individuals who were not part of the study were chosen, and official respondents were requested to do the pilot testing of the said instrument. With the assistance of an expert statistician, the reliability test was done using Cronbach's Alpha. The result has shown a .743 score making the research instrument very high and very reliable.

As a protocol in any research undertaking, the following steps were observed for the data gathering procedure. First, approval to conduct the survey was sought from the City Mayor of Bago through the Chairman of Liga ng mga Barangay at the Bago City 
Sangguniang Panglungsod. Another letter was sent to the barangay captains and the City Health Department to confirm the study's approved set.

After approval, survey questionnaires were reproduced. Before the actual conduct of the study, a brief orientation was done before the survey proper, and consent of the respondents was sought. The researcher gathered all respondents from a selected barangay health center to discuss the purpose and objectives of the study. After this, the researcher, with the help of midwives and barangay health workers, personally administered the survey questionnaires. The raw data were then tallied, tabulated, and given to an expert statistician who, in return, was tasked to assist in the statistical analysis.

The descriptive scheme was used to assess the level of literacy of mothers to polio vaccination. Comparative schemes were used to determine the significant differences among the variables mentioned above on the level of literacy among mothers. The statistical solutions were provided using frequency, mean, and standard deviation formulas.

Informed consent was obtained from the respondents to ensure a voluntary agreement on their part to participate. Each respondent was given an informed consent form, specifying the respondent's freedom to be involved in the study or not before the start of the survey.

The researcher observed data confidentiality to protect the information from being accessed by unauthorized parties. The researcher has maintained this by disallowing others to gain access to sensitive data from the research findings. The respondents' anonymity was observed during the survey; their identity was not disclosed. The data retrieved from the study were kept for safekeeping upon completion and were disposed of according to the protocols set on the disposal of data.

\section{Results and Discussion}

Profile of Respondents

Table 2 shows the demographic profile of the respondents. In terms of age, respondents between the ages of 19 and 46 accounted for $86.4 \%(n=76)$, while the respondents 18 years old below accounted for $2.3 \%(n=2)$. The majority of the respondents are high school graduates and reached high school level only, which accounted for $33.0 \%$ $(n=29)$ and $25.0 \%(n=22)$, respectively. As to the distance of health facility, the majority of the respondents or $86.4 \%(\mathrm{n}=76)$ are living near the said facility within 0 to $9 \mathrm{~km}$. Mothers with two or less children accounted for the majority with $61.4 \%(n=54)$ than mothers with three or more with $38.6 \%$ (34).

The majority of the families belong to the low family income bracket of $\mathrm{PhP}$ $1,000.00$ to $15,000.00$ with $89.8 \%(n=79)$, while $10.2 \%(n=9)$ belong to a family income bracket of PhP 16,000.00 or more. Lastly, the majority of the respondents were stratified as to their distribution and were randomly selected. In terms of distribution, four (4) barangays have the highest number of distribution of respondents with ten (10) or more: Barangay Bagroy, Dulao, Ilijan, and Barangay Poblacion, which got 11 respondents out of the total distribution of 88 respondents. 
Table 2. Demographic Profile of the Respondents

\begin{tabular}{|c|c|c|}
\hline Variable & $\mathbf{n}$ & $\%$ \\
\hline \multicolumn{3}{|l|}{ Age } \\
\hline 18 years old and below & 2 & 2.3 \\
\hline 19 to 46 years old & 76 & 86.4 \\
\hline 47 years old and up & 10 & 11.4 \\
\hline \multicolumn{3}{|l|}{ Educational Attainment } \\
\hline Elementary Level & 6 & 6.8 \\
\hline Elementary Graduate & 7 & 8 \\
\hline High School Level & 22 & 25 \\
\hline High School Graduate & 29 & 33 \\
\hline College Level & 14 & 15.9 \\
\hline College Graduate & 10 & 11.4 \\
\hline \multicolumn{3}{|l|}{ Distance of he alth facility } \\
\hline O to $9 \mathrm{~km}$ & 76 & 86.4 \\
\hline $10 \mathrm{~km}$ and up & 12 & 13.6 \\
\hline \multicolumn{3}{|l|}{ No. of Children } \\
\hline 2 or less & 54 & 61.4 \\
\hline 3 or more & 34 & 38.6 \\
\hline \multicolumn{3}{|l|}{ Family Income } \\
\hline Php 1, OOO to Php 15,0OO & 79 & 89.8 \\
\hline Php 16,000 or more & 9 & 10.2 \\
\hline \multicolumn{3}{|l|}{ Barangay } \\
\hline Alianza & 7 & 8 \\
\hline Bagroy & 10 & 11.4 \\
\hline Caridad & 9 & 10.2 \\
\hline Dulao & 10 & 11.4 \\
\hline Ilijan & 10 & 11.4 \\
\hline Lag-asan & 6 & 6.8 \\
\hline Maao & 9 & 10.2 \\
\hline Pacol & 9 & 10.2 \\
\hline Poblacion & 11 & 12.5 \\
\hline Taloc & 7 & 8 \\
\hline Total & $\mathbf{8 8}$ & 100 \\
\hline
\end{tabular}




\section{Literacy of Mothers on Polio Vaccination}

As a whole, the literacy level of mothers on polio vaccination is very high $(\mathrm{M}=37.84$, $\mathrm{SD}=1.52)$. In terms of age, those who are 18 years old and below rated lowest__ $(\mathrm{M}=36$, $\mathrm{SD}=4.24)$, while those who are 19 years old rated _high__ $(\mathrm{M}=37.83, \overline{\mathrm{S} D}=1.48)$, and those who are 47 years old rated middle__ $(\mathrm{M}=38.30, \mathrm{SD}=1.06)$. Even in the following areas: polio literacy facts, benefits of polio, and effects of polio, all got very high scores. In educational attainment, college-level mothers scored the highest $(\mathrm{M}=38.07, \mathrm{SD}=1.00)$, followed by high school level $(\mathrm{M}=38.05, \mathrm{SD}=1.53)$ and elementary level $(\mathrm{M}=38.00$, $\mathrm{SD}=2.61)$. Elementary graduates scored $8 \% \quad(\mathrm{M}=37.86, \mathrm{SD}=1.07)$, while high school graduates scored __ $(\mathrm{M}=3.62, \mathrm{SD}=1.78)$, and college graduates scored __ $(\mathrm{M}=37.60$, $\mathrm{SD}=0.84)$.

When it comes to distance, mothers showed very high literacy; those living below 10 kilometers from the health center scored $(\mathrm{M}=37.68, \mathrm{SD}=1.58)$ while those living 10 kilometers away from the health center scored _ $(\mathrm{M}=38.83, \mathrm{SD}=0.39)$. Having more children is not a barrier to the consumption of the polio vaccine because both groups exhibited a very high level of literacy. Mothers with two or less children scored $(\mathrm{M}=37.89$, $\mathrm{SD}=1.45$ ), and mothers with three or more children scored $(\mathrm{M}=37.76, \mathrm{SD}=1.65)$. Mothers with high or less income also scored very high in their literacy: mothers having an income of $\mathrm{P} 15,000$ and below $(\mathrm{M}=37.86, \mathrm{SD}=1.57)$ and mothers with an income of $\mathrm{P} 16,000$ or more $(\mathrm{M}=37.67, \mathrm{SD}=1.00)$. All barangays scored very high: Alianza $(\mathrm{M}=38.57$, $\mathrm{SD}=0.53)$, Bagroy $(\mathrm{M}=38.00, \mathrm{SD}=1.70)$, Caridad $(\mathrm{M}=38.11, \mathrm{SD}=0.33)$, Dulao $(\mathrm{M}=38.10$, $\mathrm{SD}=0.88)$, Ilijan $(\mathrm{M}=37.70, \mathrm{SD}=1.42)$, Lag-asan $(\mathrm{M}=36.50, \mathrm{SD}=2.17)$, Maao $(\mathrm{M}=37.44$, $\mathrm{SD}=1.88)$, Pacol $(\mathrm{M}=39.00, \mathrm{SD}=0.00)$, Poblacion $(\mathrm{M}=36.73, \mathrm{SD}=2.15)$, and Taloc $(\mathrm{M}=38.29, \mathrm{SD}=0.95)$.

Filipino mothers believe that vaccination is important. They have a very high literacy level of polio vaccine in the areas of facts, benefits, and effects. They know that this is one of the most important vaccinations. This result is similar to the results of the study of Nanbur et al. (2019) on polio in Nigeria, which is in the top 3 polio-stricken countries worldwide, where most of the respondents who were mothers knew about polio and its vaccine. Also, the study of Khan (2015) proved that almost all respondents who were also mothers were optimistic about the polio vaccine and were happy having their children vaccinated with polio. The mothers' high knowledge of the disease dramatically influences their positive response to the polio vaccine (Jheeta, 2008). In this study, mothers have a very positive response to polio vaccination. 
Table 3. Level of Literacy on Polio Vaccination of Mothers

\begin{tabular}{|c|c|c|c|c|c|c|c|c|c|c|c|c|}
\hline \multirow{2}{*}{ Variable } & \multicolumn{3}{|c|}{ Literacy } & \multicolumn{3}{|c|}{ Polio Literacy Facts } & \multicolumn{3}{|c|}{ Benefits of Polio } & \multicolumn{3}{|c|}{ Effects of Polio } \\
\hline & $\mathbf{M}$ & SD & Int & $\mathbf{M}$ & SD & Int & $\mathbf{M}$ & SD & Int & $\mathbf{M}$ & SD & Int \\
\hline \multicolumn{13}{|l|}{ Age } \\
\hline 18 years old and below & 36 & 4.24 & VH & 17 & 4.24 & $\mathrm{VH}$ & 9.5 & 0.71 & VH & 9.5 & 0.71 & $\mathrm{VH}$ \\
\hline 19 to 46 years old & 37.8 & 1.48 & VH & 18.46 & 1.23 & $\mathrm{VH}$ & 9.88 & 0.33 & VH & 9.49 & 0.5 & $\mathrm{VH}$ \\
\hline 47 years old and up & 38.3 & 1.06 & VH & 18.4 & 1.17 & $\mathrm{VH}$ & 10 & 0 & VH & 9.9 & 0.32 & $\mathrm{VH}$ \\
\hline \multicolumn{13}{|l|}{ Educational Attainment } \\
\hline Elementary Level & 38 & 2.61 & VH & 18.5 & 2.26 & $\mathrm{VH}$ & 9.67 & 0.52 & VH & 9.83 & 0.41 & $\mathrm{VH}$ \\
\hline Elementary Graduate & 37.9 & 1.07 & VH & 18.43 & 1.4 & $\mathrm{VH}$ & 9.86 & 0.38 & VH & 9.57 & 0.53 & $\mathrm{VH}$ \\
\hline High School Level & 38.1 & 1.53 & VH & 18.64 & 1.33 & $\mathrm{VH}$ & 9.91 & 0.29 & VH & 9.5 & 0.51 & $\mathrm{VH}$ \\
\hline High School Graduate & 37.6 & 1.78 & VH & 18.28 & 1.41 & $\mathrm{VH}$ & 9.83 & 0.38 & VH & 9.52 & 0.51 & $\mathrm{VH}$ \\
\hline College Level & 38.1 & 1 & VH & 18.64 & 0.93 & $\mathrm{VH}$ & 10 & 0 & VH & 9.43 & 0.51 & $\mathrm{VH}$ \\
\hline College Graduate & 37.6 & 0.84 & VH & 18 & 0.47 & $\mathrm{VH}$ & 10 & 0 & VH & 9.6 & 0.52 & $\mathrm{VH}$ \\
\hline \multicolumn{13}{|l|}{ Distance } \\
\hline 0 to 9 & 37.7 & 1.58 & VH & 18.22 & 1.27 & $\mathrm{VH}$ & 9.87 & 0.34 & VH & 9.59 & 0.49 & $\mathrm{VH}$ \\
\hline 10 and up & 38.8 & 0.39 & VH & 19.67 & 0.65 & $\mathrm{VH}$ & 10 & 0 & VH & 9.17 & 0.39 & $\mathrm{VH}$ \\
\hline \multicolumn{13}{|l|}{ No. of Children } \\
\hline 2 or less & 37.9 & 1.45 & VH & 18.48 & 1.18 & $\mathrm{VH}$ & 9.89 & 0.32 & $\mathrm{VH}$ & 9.52 & 0.5 & $\mathrm{VH}$ \\
\hline 3 or more & 37.8 & 1.65 & $\mathrm{VH}$ & 18.32 & 1.49 & $\mathrm{VH}$ & 9.88 & 0.33 & $\mathrm{VH}$ & 9.56 & 0.5 & $\mathrm{VH}$ \\
\hline \multicolumn{13}{|l|}{ Income } \\
\hline Php1,000 to Php15,000 & 37.9 & 1.57 & VH & 18.44 & 1.35 & $\mathrm{VH}$ & 9.87 & 0.33 & VH & 9.54 & 0.5 & $\mathrm{VH}$ \\
\hline Php 16,000 or more & 37.7 & 1 & VH & 18.22 & 0.83 & $\mathrm{VH}$ & 10 & 0 & VH & 9.44 & 0.53 & $\mathrm{VH}$ \\
\hline \multicolumn{13}{|l|}{ Barangay } \\
\hline Alianza & 38.6 & 0.53 & VH & 18.57 & 0.53 & $\mathrm{VH}$ & 10 & 0 & $\mathrm{VH}$ & 10 & 0 & $\mathrm{VH}$ \\
\hline Bagroy & 38 & 1.7 & VH & 18.5 & 1.18 & $\mathrm{VH}$ & 9.9 & 0.32 & VH & 9.6 & 0.52 & $\mathrm{VH}$ \\
\hline Caridad & 38.1 & 0.33 & VH & 19.11 & 0.33 & $\mathrm{VH}$ & 10 & 0 & VH & 9 & 0 & $\mathrm{VH}$ \\
\hline Dulao & 38.1 & 0.88 & VH & 18.2 & 0.92 & $\mathrm{VH}$ & 10 & 0 & VH & 9.9 & 0.32 & $\mathrm{VH}$ \\
\hline Ilijan & 37.7 & 1.42 & VH & 18.2 & 1.03 & $\mathrm{VH}$ & 10 & 0 & VH & 9.5 & 0.53 & $\mathrm{VH}$ \\
\hline Lag-asan & 36.5 & 2.17 & VH & 17.5 & 1.97 & $\mathrm{VH}$ & 9.83 & 0.41 & VH & 9.17 & 0.41 & $\mathrm{VH}$ \\
\hline Maao & 37.4 & 1.88 & VH & 17.78 & 1.56 & $\mathrm{VH}$ & 9.89 & 0.33 & VH & 9.78 & 0.44 & $\mathrm{VH}$ \\
\hline Pacol & 39 & 0 & VH & 20 & 0 & $\mathrm{VH}$ & 10 & 0 & VH & 9 & 0 & $\mathrm{VH}$ \\
\hline Poblacion & 36.7 & 2.15 & VH & 17.64 & 1.69 & $\mathrm{VH}$ & 9.45 & 0.52 & VH & 9.64 & 0.5 & $\mathrm{VH}$ \\
\hline Taloc & 38.3 & 0.95 & VH & 18.71 & 0.76 & $\mathrm{VH}$ & 9.86 & 0.38 & VH & 9.71 & 0.49 & $\mathrm{VH}$ \\
\hline As a Whole & 37.8 & 1.52 & $\mathrm{VH}$ & 18.4 & 1.3 & $\boldsymbol{V H}$ & 9.89 & 0.32 & $\boldsymbol{V H}$ & 9.53 & 0.5 & $\boldsymbol{V H}$ \\
\hline
\end{tabular}

Note $: \mathrm{VH}=$ Very High

\section{Difference in the Level of Literacy of Mothers on Polio Vaccination}

Kruskal Wallis was used to determine the significant difference in the level of literacy of mothers on polio vaccination when they are grouped according to age, educational attainment, and barangay.

There is no significant difference in the level of literacy of mothers on polio vaccination when they are grouped according to age $\left[\chi^{2}(2)=0.963, p=0.618\right]$ and educational attainment $\left[\chi^{2}(5)=3.352, \mathrm{p}=0.646\right]$. On the other hand, there is a significant difference in the level of literacy of mothers on polio vaccination when they are grouped according to barangay $\left[\chi^{2}(9)=19.156, p=0.024\right]$. Residents from Lag-asan scored significantly lower than residents from Dulao, Caridad, Taloc, Alianza, and Pacol. 
In the study of Khan et al. (2017), maternal factors such as education and age were among the few elements that were mostly associated with complete vaccination against polio. With the increasing age, mothers are more likely to understand better the things needed by their children, such as having their children vaccinated.

In contrast, mothers with higher educational attainment are more likely to submit their children for vaccination because of the increasing knowledge from education. In this study, there are no significant differences in the level of literacy of mothers on polio vaccination when they are grouped according to age and educational attainment.

Barangays, as a social and political structure in the Philippines, have been used extensively to deliver essential health and other services. The significant difference in the level of literacy among mothers when grouped according to barangay can be attributed to their location to the nearest healthcare facility where polio immunization is given. In 2019, the Red Cross Organization in the Philippines, through its chairman, Richard Gordon, announced its support to the Department of Health campaign to vaccinate children in the hardest-to-reach communities. He further stated that factors that may contribute to the spread of polio and diseases such as dengue and measles might include many factors, including inadequate access to health care. The accessibility to health care could be attributed to barangay locations to a health care facility to avail such services as polio vaccination. Table 4 shows the difference in the level of literacy of mothers on polio vaccination when they are grouped according to age.

Mann Whitney U test was used to determine the significant difference in the level of literacy of mothers on polio vaccination when they are grouped according to the number of children, income, and distance from the health center.

There is no significant difference in the level of literacy of mothers on polio vaccination when they are grouped according to the number of children [U=901.50, $\mathrm{p}=0.884$ ] and income [U=288.00, $\mathrm{p}=0.336]$. Meanwhile, there is a significant difference in the level of literacy of mothers on polio vaccination when they are grouped according to distance from the health center [ $\mathrm{U}=218.00, \mathrm{p}=0.003]$.

The results show that both mothers with a small number of children and mothers who have more children have ample time to understand about polio. For mothers who can be busy with children to attend to, vaccination is so important that they still have the time to understand polio vaccination. A large household is not a hindrance to the availment of the vaccine. These mothers' behavior of submitting their children to vaccination is not affected by the demographic variable number of children (Grinde \& Tambs, 2016).

Income is not a hindrance to having a high literacy in the polio vaccine. The results of the study showed that income did not make a difference in the literacy and compliance of mothers. Although there were reports of incomplete vaccination in rural areas, the wealth index is not found to differ in polio vaccination compliance (Khan, 2017).

When grouped according to distance from the health center, it is surprising to note that mothers who live more than $10 \mathrm{~km}$ from the health center have a higher literacy than those living less than $10 \mathrm{~km}$ from the health center. With good access to health care facilities, even those who live far from the health center would mean better and improved access to care (Bhatt \& Bathija, 2018). 
Table 4. Difference in the Level of Literacy of Mothers on Polio Vaccination when they are grouped according to Age

\begin{tabular}{ccccc}
\hline \multicolumn{1}{c}{ Variable } & M & $\mathbf{x 2}$ & df & p \\
\hline Age & & & & \\
18 years old and be & 36 & & & \\
& $(4.24)$ & & & 0.618 \\
19 to 46 years old & 37.83 & 0.963 & 2 & \\
& $(1.48)$ & & & \\
47 years old and up & 38.3 & & & \\
& $(1.06)$ & & & \\
\hline
\end{tabular}

Table 5. Difference in the Level of Literacy of Mothers on Polio Vaccination when they are grouped according to Educational Attainment

\begin{tabular}{lcccc}
\hline Educational Attainment & $\mathbf{M}$ & $\mathbf{x 2}$ & $\mathbf{d f}$ & $\mathbf{p}$ \\
\hline Elementary Level & 38 & & & \\
& $(2.61)$ & & & \\
Elementary Graduate & 37.86 & & & \\
& $(1.07)$ & & & \\
High School Level & 38.05 & & & \\
& $(1.53)$ & 3.352 & 5 & \\
High School Graduate & 37.62 & & & \\
& $(1.78)$ & & & \\
College Level & 38.07 & & & \\
& $(1.00)$ & & & \\
College Graduate & 37.6 & & \\
& $(0.84)$ & & \\
\hline
\end{tabular}

Table 6. Difference in the Level of Lite racy of Mothers on Polio Vaccination when they are grouped according to Distance to Health Facility

\begin{tabular}{cccc}
\hline \multicolumn{2}{l}{ Distance to Health Facility } & u & p \\
\hline 0 to 9 & $\mathbf{1 0}$ and up & & \\
\hline 37.68 & 38.83 & $218.00^{*}$ & 0.003 \\
$(1.58)$ & $(0.39)$ & & \\
\hline
\end{tabular}

Note: the difference is significant when $\mathrm{p} \leq 0.05$ 
Table 7. Difference in the Level of Literacy of Mothers on Polio Vaccination when they are grouped according to the Number of Children

\begin{tabular}{cccc}
\hline \multicolumn{2}{c}{ No. of Children } & u & p \\
\hline 2 or less & 3 or more & & \\
\hline 37.89 & 37.76 & 901.5 & 0.884 \\
$(1.45)$ & $(1.65)$ & & \\
\hline
\end{tabular}

Note: the difference is significant when $\mathrm{p} \leq 0.05$

Table 8. Difference in the Level of Literacy of Mothers on Polio Vaccination when they are grouped according to Family Income

\begin{tabular}{|c|c|c|c|}
\hline \multicolumn{2}{|c|}{ Income } & \multirow[t]{2}{*}{$\mathbf{u}$} & \multirow[t]{2}{*}{$\mathbf{p}$} \\
\hline Php 1,000 to Php 15,000 & Php 16,000 or more & & \\
\hline $\begin{array}{c}37.86 \\
(1.57) \\
\end{array}$ & $\begin{array}{l}37.67 \\
(1.00) \\
\end{array}$ & 288 & 0.336 \\
\hline
\end{tabular}

Note: the difference is significant when $\mathrm{p} \leq 0.05$

Table 9. Difference in the Level of Literacy of Mothers on Polio Vaccination when they are grouped according to Barangay

\begin{tabular}{|c|c|c|c|c|}
\hline Barangay & $\mathbf{M}$ & $\mathrm{x2}$ & df & $\mathbf{p}$ \\
\hline Alianza & $\begin{array}{l}38.57_{c} \\
(0.53)\end{array}$ & & & \\
\hline Bagroy & $\begin{array}{c}38.00_{\mathrm{abc}} \\
(1.70)\end{array}$ & & & \\
\hline Caridad & $\begin{array}{c}38.11_{\mathrm{bc}} \\
(0.33)\end{array}$ & & & \\
\hline Dulao & $\begin{array}{c}38.10_{\mathrm{bc}} \\
(0.88)\end{array}$ & & & \\
\hline Ilijan & $\begin{array}{c}37.70_{\mathrm{abc}} \\
(1.42)\end{array}$ & $19.156^{*}$ & 9 & 0.024 \\
\hline Lag-asan & $\begin{array}{l}36.50_{\mathrm{a}} \\
(2.17)\end{array}$ & & & \\
\hline Maao & $\begin{array}{c}37.44_{\mathrm{abc}} \\
(1.88)\end{array}$ & & & \\
\hline Pacol & $\begin{array}{c}39.00_{\mathrm{c}} \\
0\end{array}$ & & & \\
\hline Poblacion & $\begin{array}{l}36.73 \\
(2.15)\end{array}$ & & & \\
\hline Taloc & $\begin{array}{c}38.29 \mathrm{bc} \\
(0.95)\end{array}$ & & & \\
\hline
\end{tabular}

Note: the difference is significant when $\mathrm{p} \leq 0.05$ 


\section{Reasons for Mothers' Compliance with Polio Vaccination}

Compliance with health care services and treatments such as polio vaccination involves many factors, especially why mothers submit their children for vaccination. The table shows that the leading reason for mothers' compliance with polio vaccination in selected barangays of Bago City is that there are health workers who give follow-up through home visits, which accounted for $39.8 \%(n=35)$. The second highest reason mothers comply with polio vaccination is that any health professional can give the vaccine, which accounted for $37.5 \%(n=33)$. These top two reasons can be attributed to the fact that mothers can easily access the said service in the health facility available in their area. This leads to the idea that access to health care services is essential in promoting health, especially in polio vaccination, which prevents polio development. Accessibility to these services is facilitated by health workers and health professionals who, in turn, play an essential role in the compliance of mothers to polio vaccination. The availability of health care professionals and workers in doing follow-ups through home visits and identifying who they can readily give the vaccine makes polio vaccination very efficient in terms of compliance.

In a study by Smith (2017) on compliance of caregivers with polio vaccine, it was concluded that the caregivers (health workers) are the crucial link to ensuring that all recommended polio vaccine doses are received and done on time. In a sense, compliance with polio vaccination is the mothers' responsibility for their children and the caregivers or health workers since they make sure that the compliance can be guaranteed.

In a study conducted in the Philippines, it was concluded that the awareness of mothers on vaccination was associated with the completion of immunization. This goes to show that awareness is associated with compliance with complete immunization, including polio vaccination. The result of the literacy of mothers on polio vaccination in selected barangays of Bago City is more than enough to equate its result on compliance of mothers with polio vaccination on awareness of mothers on vaccination and completion of immunization (Barangan \& Mariano, 2017).

The role of health professionals and health workers was crucial in the compliance of mothers with polio vaccination. Without them, proper information-dissemination cannot be attained, which will affect the mothers' awareness or literacy on polio vaccination. They are the two major reasons why mothers submitted their children to polio vaccination. Their availability in giving the vaccine and their constant follow up through home visits to ensure that mothers have their children submitted to polio vaccination are essential in polio vaccination compliance.

However, with the current pandemic, the compliance rate may be affected by fear of being contaminated, quarantined in some areas, and the availability of vaccines. Therefore, the Local Government Unit (LGU) needs to bring health services closer to the people amidst the presence of the pandemic. In the results, health care workers were diligent in making a follow-up of children for vaccination because it is the number one reason mothers bring their children for vaccination. 
Table 10. Reasons for Mothers for Compliance with Polio Vaccination

\section{Conclusion}

The significant level of very high literacy of mothers on polio vaccination shows the accessibility of people to the essential health care services of the country, particularly on polio vaccination. The distance and location of a health care facility play an essential role in the compliance of health care services. Health care utilization, such as polio vaccination, can only be effective if the recipients of care have a very high literacy on the health services provided in an area strategically located where the people are residing. The health workers implement the mandate on EPI, which is shown in the very high literacy of the mothers. The perception of the mothers in polio vaccination was strengthened by the health workers, which in turn strengthened their belief in health promotion and sickness prevention. Strengthening the belief, as the goal of the Health Belief Model, makes these mothers comply with the mandate.

\section{Recommendations}

Based on the results and conclusions of the study, the following are the recommendations:

Rural health administrators. Rural health administrators should conduct a reassessment on the implementation of their vaccination program on polio to strengthen the campaign to bring back the polio-free status of the country. They should initiate a massive information-dissemination campaign to enhance the literacy of mothers on polio vaccination. Above all, health networks should be developed to address the poor accessibility of health care services such as polio vaccination for people located far from the health care facility.

Community health nurses. Their role in the delivery of health care services such as polio vaccination should be properly supported by giving them enhancement training to maximize the delivery of essential health services for people in the community.

Future researchers. Future researchers are encouraged to explore the associations of the variables studied or other variables that will support the campaign for a polio-free country.

\section{Acknowledgement}

The authors extend their heartfelt appreciation to Dean Arnibal and Dean Madrigal for their helpful suggestions, corrections and ideas they provided to complete this study; to the mothers in the community who took time to participate in this study; and also, the support of the rural health administrators is greatly appreciated. Moreover, the authors are always grateful for the never-ending encouragement of their family who believes in them in making this study a successful one. 


\section{Funding}

This study did not receive any specific contribution from any funding agency particularly in the public or non-profit sectors.

\section{Author's Contribution}

K. Vinco contributed to the research concept and design, data collection and data analysis. K. Vinco enlisted the introduction and conducted data collection. X. Malaga analyzed the data. K. Vinco wrote the discussions and analysis of the data and X. Malaga reviewed the data analysis. All authors read and approved the final manuscript.

K. Vinco is a Head Nurse of South Bacolod General Hospital and Medical Center Inc. in Bacolod City, Philippines. She is a Registered Nurse in the Philippines currently assigned in the Neonatal Intensive Care Unit. She practiced clinical nursing for 12 years.

Originally, portions of this article appeared in K. Vinco's thesis study, Polio Vaccination Literacy Among Mothers of Selected Barangay Health Centers in a Component City, 2020, while she was a student in the Recoletos de Bacolod Graduate School at the University of Negros Occidental - Recoletos in Bacolod City, Negros Occidental, Philippines, under the supervision of X. Malaga.

X. Malaga is a Health Policy and Systems Research Fellow at the Department of Health Region VI Western Visayas Center for Health and Development in the Philippines. He is also a research adviser in the Recoletos de Bacolod Graduate School at the University of Negros Occidental - Recoletos in Bacolod City, Negros Occidental, Philippines. He is also a Registered Nurse and currently finishing his career for Doctor of Philosophy in Nursing in the Philippines.

\section{Disclosure Statement}

The authors reported that there was no potential conflict of interest in making this study.

\section{References}

[1] Al Agili D. E. \& Griffin, S. O. Effect of Family Income on the Relationship Between Parental Education and Sealant Prevalence, National Health and Nutrition Examination Survey, 2005-2010. Prev Chronic Dis 2015;12:150037. DOI: http://dx.doi.org/10.5888/pcd12.150037external icon

[2] Almond, D. (2006). Is the 1918 Influenza Pandemic Over? Long-Term Effects of In Utero Influenza Exposure in the Post-1940 U.S. Population. The University of Chicago Press Journal, 672-712.

[3] Anderson, J. (2014). The Impact of Family Structure on the Health of Children: Effects of Divorce. The Linacre Quarterly, 81(4), 378-387. Retrieved from https://doi.org/10.1179/0024363914Z.00000000087

[4] Bandyopadhyay, A. S. (2019, July). Centers for Disease Control and Prevention. Retrieved March 2020, from CDC Centers for Disease Control and Prevention: wwwnc.cdc.gov

[5] Azhar, S., Saeed, H., Syed, A., Khalid, S., Bukhari, A., \& Murtaza, G. (2016, November). Value in Health Journal. Retrieved March 2020, from Value in Health Journal: valueinhealthjournal.com/article/S1098-3015(16)33018-2/fulltext

[6] Baranga, R. \& Mariano, C. (2017). Factors affecting Compliance to the Expanded Program of Immunization of Children 2 years old and below in Barangay Tabing-Ilog, Marilao, Bulacan. Manila. Philippines. http://www.hkjpaed.org/aspr2017/detail.asp?id=206

[7] Bhatt, Jay DO, MPH, MPA; Bathija, Priya J.D., MHSA. Ensuring Access to Quality Health Care in Vulnerable Communities, Academic Medicine: September 2018 - Volume 93 - Issue 
9 - p 1271-1275 doi: 10.1097/ACM.0000000000002254

[8] Bruer, J. T. (2016). Schools for Thought: A Science of Learning in the Classroom. Retrieved from American Psychological Association: https://psycnet.apa.org/record/1993-97456000

[9] Bustreo, F. \& Okwo-Bele, J. M. K. (2016). World Health Organization Perspectives on the Contribution of the Global Alliance for Vaccines and Immunization on reducing Child Mortality. BMJ Journals.

[10] CDC (2018, May 4). CDC Centers for Disease Control and Prevention. Retrieved from Vaccines and Preventable Diseases: https:/www.cdc.gov/vaccines/vpd/polio/index.html

[11] Chaudry, A. \& Wimer, C. (2016). The Relationship Between Income, Poverty, and Child: DOI:https://doi.org/10.1016/j.acap.2015.12.010

[12] Coe, A. B., Gatewood, S. B., Moczygemba, L. R., Goode, J. V., \& Beckner, J. O. (2012). The Use of the Health Belief Model to assess Predictors of Intent to receive the Novel (2009) H1N1 Influenza Vaccine. Innovations in Pharmacy, 3(2), 1-11. https://doi.org/10.24926/iip.v3i2.257

[13] Culatta, R. (2018, November 30). InstructionalDesign.org. Retrieved from Subsumption Theory (David Ausubel): https://www.instructionaldesign.org/theories/subsumption-theory/

[14] Deeks, A., Lombard, C., Michelmore, J. et al. The Effects of Gender and Age on Health-Related Behaviors. BMC Public Health 9, 213 (2009). https://doi.org/10.1186/1471-2458-9-213

[15] Dobe, M., Ray, S. K., Biswas, R., Mandal, A., Meheta, P., \& Baishya, A. C. Evaluation of Pulse Polio Immunization in some districts of West Bengal and Assam. Indian J Public Health. 2004;48(2):88-95.

[16] Duintjer Tebbens RJ1, P. M. (2013). Expert Review on Poliovirus Immunity and Transmission. NCBI.

[17] Famulare, M., Selinger, C., McCarthy, K. A., Eckhoff, P. A., \& Chabot-Couture, G. (2018, March 28). PLOS Biology. Retrieved April 2018, 2018, from PLOS Biology: https://doi.org/10.1371/journal.pbio.2002468

[18] Forshaw, J., Gerver, S. M., Gill, M., Cooper, E., Manikam, L., \& Ward, H. (2017). The Global Effect of Maternal Education on Complete Childhood Vaccination: A Systematic Review and Meta-analysis. BMC Infectious Diseases, 17(1), 801. HYPERLINK "https://doi.org/10.1186/s12879-017-2890-y" https://doi.org/10.1186/s12879-017-2890y.

[19] George Shirreff, M. Z. (2017, February). CDC Centers for Disease Control and Prevention. Retrieved March 2020, from CDC Centers for Disease Control and Prevention: wwwnc.cdc.gov/eid/article/23/2/16-1210_article

[20] Girmay, A. \& Dadi, A. F. (2019). Full Immunization Coverage and Associated Factors among Children Aged 12-23 Months in a Hard-to-Reach Areas of Ethiopia. Ethiopia https://doi.org/10.1155/2019/1924941

[21] Grinde, B. \& Tambs, K. (2016). Effect of Household Size on Mental Problems in Children: Results from the Norwegian Mother and Child Cohort Study. BMC psychology, 4(1), 31. https://doi.org/10.1186/s40359-016-0136-1

[22] Hajizadeh, M. (2018). Socioeconomic Inequalities in Child Vaccination in Low/middle-income Countries: What accounts for the Differences? School of Health Administration, Faculty of Health, Dalhousie University, Halifax, Nova Scotia, Canada. 2018; 72:719-725.

[23] Imperial. (2016, December 3). How to Calculate a Reliable sample size using Taro Yamane Method. Retrieved from Uni project Materials: https:/uniprojectmaterials.com/viewblog/how-to-calculate-a-relaible-sample-size-using-taro-yamane-method

[24] Jheeta, M. N. J. (2008). Childhood Vaccination in Africa and Asia: The Effects of Parents' Knowledge and Attitudes. Bulletin of the World Health Organization, 417-496.

[25] Joseph, N., Subba, S., Nelliyanil, M., Kotian, S., Haridath A., N. K. et al. A Study of the Knowledge and Attitude towards Pulse Polio Immunization in Semi-urban Areas of South 
India. Australas Med J. 2011;4(2):81-6.

[26] Khan MU, A. A. (2015). BMC Public Health. Retrieved from BMC Public Health: https://doi:10.1186/s12889-015-2471-1

[27] Khan MU, A. A. (2015). Knowledge, Attitudes, and Perceptions towards Polio Immunization among Residents of two highly affected Regions of Pakistan. BMC Public Health.

[28] Khan, M. T., Zaheer, S., \& Shafique, K. (2017, March 10). U.S. National Library of Medicine National Institutes of Health. Retrieved March 2020, from NCBI: ncbi.nlm.nih.gov/pmc/articles/PMC5353333

[29] Khan M. T., Zaheer, S., \& Shafique, K. Maternal (2017). Education, Empowerment, Economic Status, and Child Polio Vaccination Uptake in Pakistan: A Population-based Cross-sectional Study BMJ Open 2017;7:e013853. doi: 10.1136/bmjopen-2016-013853

[30] Man Mohan Mehndiratta, P. M. (2014, October). NCBI. Retrieved March 2020, from U.S. National Library of Medicine National Institutes of Health: www.ncbi.nlm.nih.gov

[31] Matsuzawa, M. (2019, September 20). Polio's Resurgence in the Philippines: The ancient disease was supposed to be extinct last year. PhilStar Global.

[32] McNeil, D. M. (2019). BMC Public Health. Retrieved from BMC Public Health: https://doi.org/10.1186/s12889-018-6338-0

[33] MENA Report (2019): Philippines: Red Cross Triples Polio Vaccination Target. Washington, D. C. Retrieved from https://search.proquest.com/docview/2311077251?accountid=28547

[34] Nanbur, S. Y. (2019). Knowledge, Attitude, and Practice of Mothers towards the Acceptance of Oral Polio Vaccine for their Children. International Journal of Medical and Health Research.

[35] Nanbur, S., Yimi, S. P., Joseph, G. N., P, T., \& Nannim, N. (2019, May 4). International Journal of Medical and Health Research. Retrieved March 2020, from Medical Science Journal: www.medicalsciencejournal.com

[36] Nickolas, S. (2019, July 14). How Stratified Random Sampling Works. Retrieved from Investopedia: https://www.investopedia.com/ask/answers/032615/what-are-someexamples-stratified-random-sampling.asp

[37] Osowole OS, O. J. (2005). princeton.edu. Retrieved from princeton.edu: http://iussp2005princeton.edu/papers/50810

[38] Picciano, A. (2018). Education Research Methods. Retrieved from EDTATS Primer Session 8 Correlational Research: https://www.anthonypicciano.com/s8.html

[39] Podderl, D., Dasgupta, B. P., Bandyopadhyay, L., Pal, A., \& Roy, S. (2019). Medical Journal of Dr. D.Y. Patil Vidyapeeth. Retrieved March 2020, from MJDRDYPV: mjdrdypv.org

[40] Quitevis, R. B. (2011). Level of Acceptability of Roles and Performance of Barangay Health Workers in the Delivery of Basic Health Services. UNP Research Journal, 20(1). Retrieved from http://ejournals.ph/form/cite.php?id=6931

[41] Radboud J., Tebbens, D., Pallansch, M., Cochi, S., Wassilak, S., Linkins, J. Sutter, R., Award, B., Thompson, K. Economic Analysis of the Global Polio Eradication Initiative. Volume 29, Issue 2, December 16, 2010, Pages 334-343

[42] Ratzan, S. M. (2011). Vaccine Literacy, a Crucial Healthcare Innovation. Harvard Business Review Home.

[43] Richardson, H. (2018, June 28). Characteristics of a Comparative Research Design. Retrieved from Classroom Synonym: https://classroom.synonym.com/characteristicscomparative-research-design-8274567.html

[44] Salako-Smith, G. O. (2017). Compliance of Caregivers with Polio Vaccine: Dosages and Timelines in Lagos State Nigeria. USAhttps://scholarworks.waldenu.edu/cgi/viewcontent.cgi? article $=5021 \&$ context $=\mathrm{di}$ ssertations

[45] Santoli, J. M., Lindley, M. C., De Silva, M. B. et al. Effects of the COVID-19 Pandemic on Routine Pediatric Vaccine Ordering and Administration. United States, 2020. MMWR Morb 
Mortal Wkly Rep 2020;69:591-593. DOI: http://dx.doi.org/10.15585/mmwr.mm6919e2

[46] Sophie Ochmann, M. R. (2017, November 9). Our World In Data. Retrieved March 2020, from Our World in Data: ourworldindata.org

[47] Stickle, G. (1964, August). Observed and Expected Poliomyelitis in the United States, 19581961. Am J Public Health Nations Health, 1222-1229.

[48] Stock, R. (2002). Distance and the Utilization of Health Facilities in Rural Nigeria. Ontario, Canada. https://doi.org/10.1016/0277-9536(83)90298-8

[49] Sulaiman, S. K., Aldersey, H. M., Fayed, N., \& Kaka, B. (2020, January 17). Springer Link. Retrieved March 2020, from Springer Link: link.springer.com

[50] Sumerido, V. (2016, February 17). Neg Occ has the highest polio risk in W. Visayas; immunization set. SunStar Philippines.

[51] Verulava, T., Jaiani, M., Ana Lordkipanidze, R. J., \& Dangadze, b. (2019). Bentham Open. Retrieved from Bentham Open: benthamopen.com/FULLTEXT/TOPHJ-12-232

[52] WHO (2012, July). Oral Poliomyelitis Vaccine (OPV). Retrieved from World Health Immunization.https://www.who.int/immunization_standards/vaccine_quality/qa_production_ control_pq_11july2012.pdf?ua $=1$

[53] WHO (2019, September 19). WHO. Retrieved from WHO: https://www.who.int/philippines/news/detail/19-09-2019-who-unicef-and-partnerssupport-philippine-department-of-health-s-polio-outbreak-response

[54] WHO, W. H. (2019, July 22). Poliomyelitis. Retrieved March 4, 2020, from World Health Organization: WHO.int

[55] World Health Organization (2019, April 2019). Retrieved March 2020 from World Health Organization: WHO.int

[56] Yambo, M. (2016). KAP as a Model of Behavior Change and Innovative Practice. Mauri Yamboo Blogging

[57] Zajacova, A. \& Lawrence, E. M. (2018). The Relationship between Education and HealthReducing Disparities Through a Contextual Approach. Annual Review of Public Health, 39, 273-289. https://doi.org/10.1146/annurev-publhealth-031816-044628 